\title{
ИНФАНТИЛИЗАЦИЯ ПОЖИЛЫХ ЛЮДЕЙ В ПОВСЕДНЕВНОМ ВЗАИМОДЕЙСТВИИ: К ПОСТАНОВКЕ ПРОБЛЕМЫ
}

В контексте проблемы трансформации отношения к старости и распространения идеологии продуктивного старения пристального внимания заслуживают факторы, препятствующие формированию представлений о старости как об активном и продуктивном периоде жизни. В статье предлагается обсуждение одного из таких препятствий - инфантилизации пожилых людей. Инфантилизация понимается как модель взаимодействия, основанная на негативных геронтостереотипах, представляющая собой обращение с пожилым человеком как с ребенком. Геронтостереотипы содержат представления о том, что в пожилом возрасте человек теряет многие возможности, становясь «похожим на ребенка», что является основанием для инфантилизирующего отношения к пожилым людям во взаимодействии с ними и восприятия такого взаимодействия как нормативного и закономерного. В статье представлены результаты исследования инфантилизации пожилых людей в повседневном взаимодействии. Показано, что инфантилизирующие воздействия чаще всего фиксируются пожилыми людьми во внутрисемейном взаимодействии (со стороны представителей младших поколений семьи детей и внуков). В основе такого отношения к пожилым людям лежит представление об их неспособности принимать самостоятельные решения, осуществлять продуктивную деятельность и нести ответственность. Инфантилизирующее отношение к себе испытывают, прежде всего, те пожилые, социальная активность которых ограничена пределами семьи: не работающие, не имеющие супруга или супруги и проживающие с детьми и внуками. На основе анализа полученных результатов формулируется вывод о том, что распространенность практики инфантилизирующих отношений к пожилым людям в сфере семейных отношений

Анастасия Владимировна Микляева - д.п.н., доцент, профессор кафедры психологии человека Российского государственного педагогического университета им. А. И. Герцена, Санкт-Петербург, Россия. Электронная почта: a.miklyaeva@gmail.com 
обусловлена доминированием медицинского дискурса старости и старения в противовес идее «успешного старения». Также обнаружена гендерная асимметрия инфантилизирующего отношения к пожилым людям, связанная с феноменом «двойных стандартов старения». Обсуждение негативных последствий инфантилизации пожилых людей может стать первым шагом на пути преодоления этого явления.

Ключевые слова: инфантилизация, геронтостереотипы, пожилые люди, семья, гендер

DOI: $10.17323 / 727-0634-2018-16-1-109-124$

На фоне нарастающего старения населения происходит изменение отношения к старости, отмечается тенденция трансформации взглядов на роль пожилых людей в общественных отношениях (Бельцова 2012). В этой связи возникает идея «продуктивной старости», приходящая на смену представлениям о старости как периоде «потребности в заботе». Поэтому большое значение приобретает изучение факторов, способствующих и препятствующих изменению социальных представлений о старости, и, как следствие, реального положения пожилых людей. Эта статья посвящена одному из препятствий на пути указанных процессов - инфантилизации пожилых людей, которая, как показывают результаты исследования, является устойчивым паттерном отношения к пожилым людям, противоречащим идеям продуктивного и активного старения.

Социологические и социально-психологические исследования рассматривают инфантилизацию как проблему молодого поколения, поскольку она понимается как тенденция к «откладыванию взросления» (см.: Толстых 2015; Arnett 2011). Между тем, у понятия «инфантилизация» есть и иное значение: с помощью него обозначается особая модель взаимодействия, для которой характерно обращение с субъектом, не являющимся ребенком, таким образом, как будто он или она - ребенок. В этом значении инфантилизация рассматривается как проблема детско-родительских отношений, при которой объектом инфантилизации выступает подросток, а субъектом - его родители, по тем или иным причинам не готовые признавать его взросление (см.: Аликин, Лукьянченко 2012; Couture 2007). Однако внимание исследователей привлекает новый ракурс проблемы инфантилизации - в отношении пожилых людей.

Инфантилизация пожилых людей представляет собой особую модель поведения, для которой характерно взаимодействие с пожилым человеком как с ребенком, использование способов коммуникации, характерных для общения с детьми (Marson, Powel 2014; Gresham 1976). В отечественных и зарубежных исследованиях описаны разнообразные поведенческие паттерны, посредством которых инфантилизация пожилых в повседневном взаимодействии находит очевидное выражение: упрощение словаря, мед- 
ленный темп беседы, большое количество повторов и уточняющих вопросов, преувеличенные интонации, сопровождающиеся повышением тона голоса (babytalk), покровительственные интонации, возрастная тематизация коммуникации, использование «домашних имен» во внесемейной коммуникации (Marson 2013; Salari 2005; Елютина, Чеконова 2004; Hockey, James 1993). В перечисленных исследованиях показано, что инфантилизация пожилых людей распространенное явление, как в сфере семейного взаимодействия, так и во внесемейной коммуникации, например, при общении пожилых людей с социальными или медицинскими работниками.

Исследования, посвященные различным аспектам инфантилизации старости, позволяют утверждать, что в основе этой модели поведения лежат возрастные стереотипы, в частности, представление о пожилых людях как о некомпетентных и беспомощных (Ryan et al. 2000; Coupland et al. 1988; Caporael et al. 1983). Наиболее распространенные геронтостереотипы, касающиеся физического состояния, психического и психологического потенциала пожилых людей, отражают представления, что в пожилом возрасте человек теряет многие возможности, которые сформировались в процессе взросления, становясь «похожим на ребенка». Конструирование образа пожилого человека происходит преимущественно в контексте медицинского дискурса, акцентирующего внимание на «немощной» старости и тем самым способствующего закреплению в обществе представления о пожилых людях как больных, а, следовательно, слабых и беспомощных (Бельцова 2012; Смолькин 2004).

Как показало наше предыдущее исследование (Микляева 2014), в содержании геронтостереотипов фиксируются оппозиции, противопоставляющие пожилой возраст периоду взрослости и подчеркивающие сходства периодов старости и детства. Благодаря этому геронтостеотипы способствуют «сближению» образа пожилого человека с образом ребенка (зафиксированное, например, в крылатой фразе «старый, что малый»). Важно отметить, что стереотипное представление о частичной или полной утрате в старости «взрослых компетентностей» становится своеобразным оправданием практик инфантилизации, придавая данной модели взаимодействия статус «естественной». Более того, зарубежными исследователями показано, что субъекты, общающиеся с пожилыми людьми, часто рассматривают проявления инфантилизации в их адрес как способ оказания им психологической поддержки (Caporael et al. 1983). Однако сами пожилые люди чаще всего воспринимают подобное обращение как неуважительное, оно негативно сказывается на их физическом и психологическом благополучии (Matusitz et al. 2013; Castelli et al. 2005). Это дает основания рассматривать инфантилизацию пожилых как форму жестокого обращения с ними (Salari 2005), особую разновидность психологического насилия (Пучков 2009), способствующую формированию зависимой позиции пожилого человека, лишению возможности принимать решения, в том числе и те, которые связаны с его 
собственной жизнью. Инфантилизация может затрагивать регуляторную, нравственную или рефлексивную сферы личности, проявляясь, соответственно, в последовательной недооценке возможностей пожилого человека управлять собственной жизнью, выносить адекватные оценки поступкам и событиям или не зависеть от мнения окружающих (Микляева 2016).

Таким образом, изучение механизмов инфантилизации пожилых в практиках повседневного взаимодействия является актуальной задачей в контексте проблемы повышения качества жизни в этот период. Инфантилизация может пониматься как неконструктивная модель взаимодействия, основанная на негативных геронтостереотипах и предполагающая обращение с пожилым человеком таким образом, как если бы он был ребенком. Целью проведенного нами исследования стало описание этого феномена в повседневном взаимодействии. Теоретико-методологическую базу исследования составил социально-конструкционистский подход к пониманию старения и старости (Смолькин 2004), в рамках которого отношение к пожилым рассматривается как социально предписываемый проект, включающий набор конвенциональных правил, норм, ценностей и смыслов, опосредующих взаимодействие пожилых людей друг с другом и представителями других возрастных групп.

\section{Программа исследования}

Процедура исследования включала два этапа: (1) оценка инфантилизирующих воздействий, фиксируемых пожилыми в различных сферах собственной жизни, с помощью модифицированной методики исследования самооценки Дембо-Рубинштейн; (2) характеристика отношения к проявлениям инфантилизации в собственный адрес и ответных реакций пожилых людей, осуществляемая с использованием структурированного интервью.

Модификация методики исследования самооценки Дембо-Рубинштейн осуществлялась в соответствии с представлением о том, что личностный инфантилизм представляет собой полюс бинарного социального конструкта «зрелость личности - инфантилизм личности» (Микляева 2016). Респондентам предлагалось оценить степень личностной зрелости (актуальной и желательной) на отрезках длиной 100 мм, используя пять различных оценочных позиций: собственное мнение (самооценка), мнение членов семьи, друзей, коллег по работе (в том случае, если респондент работает в настоящее время), сотрудников различных организаций, оказывающих поддержку пожилым людям (поликлиника, собес и т.д.). Инструкция для выполнения задания предлагалась респондентам в беседе, которая служила прологом к структурированному интервью. В ходе беседы уточнялось, от чьего имени респондент оценивал себя в процессе выполнения заданий, а также возраст этого человека. В качестве проявлений инфантилизации 
во взаимодействии с пожилым человеком рассматривались случаи, в которых самооценка респондента превышала оценки, приписываемые им другим людям.

В ходе структурированного интервью прояснялся опыт столкновения респондентов с инфантилизирующими воздействиями со стороны других людей. Респонденты последовательно отвечали на вопросы: сталкивались ли они с обращением с собой как с ребенком, если «да», то с чьей стороны они замечали подобное обращение, в чем оно проявлялось, какую реакцию вызвало, как респондент относится к такого рода обращению. Полученные ответы подвергались тематической кодировке. В исследовании приняли участие 118 человек в возрасте от 64 до 81 года, из них 67 женщин и 51 мужчина, проживающие в Санкт-Петербурге, в семьях (104 человека) или одиноко (14 человек). Пожилые люди, проживающие в специализированных учреждениях, в исследовании не участвовали. Подробная характеристика представлена в таблице 1.

Таблица 1

Характеристика выборки

\begin{tabular}{llccc}
\hline & Pеспонденты & $\begin{array}{c}\text { Всего } \\
(\boldsymbol{n}=118)\end{array}$ & $\begin{array}{c}\text { Мужчины } \\
(\boldsymbol{n}=51)\end{array}$ & $\begin{array}{c}\text { Женщины } \\
(\boldsymbol{n}=\mathbf{6 7})\end{array}$ \\
\hline Род & Пенсионер & $41,5 \%$ & $58,9 \%$ & $28,4 \%$ \\
\hline Пеятельности & Работающий пенсионер & $58,5 \%$ & $41,1 \%$ & $71,6 \%$ \\
\hline & С детьми и/или внуками, & $59,1 \%$ & $72,6 \%$ & $50,8 \%$ \\
& в т.ч. с супругом / супругой & & & \\
& С супругом / супругой & $28,0 \%$ & $19,6 \%$ & $34,3 \%$ \\
& Одиноко проживающий & $11,9 \%$ & $7,8 \%$ & $14,9 \%$ \\
\hline
\end{tabular}

\section{Результаты исследования}

Полученные данные демонстрируют, что пожилые склонны приписывать людям, с которыми они взаимодействуют, более высокие оценки своих возможностей, в сравнении с самооценкой. Значения коэффициентов вариации позволяют считать совокупности оценок респондентов однородными (табл. 2). Случаи, в которых самооценка респондентов оказывается выше оценок, приписываемых ими другим людям, относительно редки и чаще всего встречаются в связи с оценочной позицией «члены семьи» (17,8\%). Для оценочных позиций «друзья» и «медицинские работники» этот показатель составляет $3,4 \%$ и 7,6\% соответственно, для оценочной позиции «коллеги» таких случаев не встречается.

В качестве субъектов, с позиции которых респонденты фиксируют отраженные самооценки, в большинстве случаев выступают люди, близкие 
к ним по возрасту. Так, в случае оценочной позиции «друзья» средняя разница в возрасте между респондентом и человеком, от имени которого осуществляется оценивание, составляет 6,16 года. Аналогичный показатель для оценочных позиций «социальные и медицинские работники» и «коллеги» составляет 12,49 и 9,3 года соответственно. Исключение - субъекты оценивания, являющиеся членами семьи: оценивание часто осуществляется с позиции детей и внуков (в 83,1\% случаев), разница в возрасте с субъектом оценивания в среднем составляет 31,3 года.

Таблица 2

Средние значения самооценки пожилых людей в континууме «зрелая личность - инфантильная личность» (в скобках указано значение коэффициента вариации для каждого показателя)

\begin{tabular}{|c|c|c|c|c|c|}
\hline \multirow{2}{*}{$\begin{array}{c}\text { Аспекты } \\
\text { оценивания }\end{array}$} & \multirow[b]{2}{*}{ Самооценка } & \multicolumn{4}{|c|}{ Оценки с позиции } \\
\hline & & $\begin{array}{c}\text { членов } \\
\text { семьи }\end{array}$ & друзей & коллег & $\begin{array}{c}\text { мед. и соц. } \\
\text { работников }\end{array}$ \\
\hline \multirow[t]{2}{*}{ Актуальная оценка } & 7,28 & 7,43 & 7,79 & 7,94 & 7,82 \\
\hline & $(27,4 \%)$ & $(25,6 \%)$ & $(21,2 \%)$ & $(19,8 \%)$ & $(17,1 \%)$ \\
\hline \multirow[t]{2}{*}{ Желательная оценка } & 8,10 & 8,21 & 8,17 & 8,32 & 8,28 \\
\hline & $(16,8 \%)$ & $(17,4 \%)$ & $(11,1 \%)$ & $(14,5 \%)$ & $(12,4 \%)$ \\
\hline
\end{tabular}

Данные, представленные в таблице 2, свидетельствуют, что самыми низкими являются именно те оценки, которые респонденты приписывают себе от имени членов семьи, по этой же оценочной позиции наблюдается самый большой разрыв между актуальной и желательной оценками. Более детальный анализ показывает, что оценки, приписываемые респондентами супруге/супругу, с одной стороны, и детям/внукам, с другой стороны, существенно различаются и составляют 7,99 и 7,01 соответственно. Таким образом, можно сделать вывод о том, что респонденты чаще всего сталкиваются с проявлениями инфантилизации в семье, прежде всего, в общении с представителями младших поколений.

Этот вывод подтверждается при анализе данных, полученных в интервью. Так, на вопрос, замечали ли они случаи, когда с пожилыми людьми обращались как с детьми, положительно отвечают 44,1\% респондентов (ответы, в которых описываются иные формы дискриминации по признаку возраста, в данном показателе не учитываются). При этом положительный ответ на этот же вопрос применительно к собственному опыту дают 26,7\% (n=31, из них 24 женщины и 7 мужчин). Ниже приводится анализ ответов тех респондентов, которые отмечают проявления инфантилизирующего отношения в свой адрес (таблица 3). Чаще всего пожилые люди фиксируют такие факты со стороны младших членов семьи: детей и внуков $(95,7 \%)$. Достоверно реже $\left(\varphi^{*}=11,76, \mathrm{p}<0,01\right)$ инфантилизирующие воздействия отмечаются со стороны 
медицинских и социальных работников (25,8\%), причем они упоминаются вместе с аналогичными внутрисемейными воздействиями.

Таблица 3

Опыт инфантилизирующего отношения, отмеченный респондентами в ходе интервью (результаты индуктивного контент-анализа) (\%)

\begin{tabular}{llc}
\hline \multicolumn{1}{c}{ Вопрос } & \multicolumn{1}{c}{ Категории ответов } & $\begin{array}{c}\text { Yастота } \\
\text { ответов }\end{array}$ \\
\hline С чьей стороны Вы замечали & дети & 66,7 \\
обращение с собой как с ребенком? & внуки & 29,0 \\
& врачи и медсестры & 16,1 \\
& сотрудники социальных служб & 9,7 \\
& другое & 6,5 \\
\hline В чем проявлялось такое обращение? & игнорирование мнения & 54,5 \\
& директивные указания & 42,4 \\
& обесценивание вклада & 25,8 \\
& преувеличенная забота & 12,1 \\
& инфантилизирующие подарки & 9,1 \\
\hline Как Вы реагировали & негативные эмоции & 51,5 \\
на такое обращение? & соглашение & 27,3 \\
& активное сопротивление & 12,1 \\
& 'подыгрывание', соглашение & \\
\hline Как Вы относитесь & с ролью ребенка с целью получе- & \\
к такому обращению? & ния той или иной выгоды & 9,1 \\
\hline & негативное отношение & 57,6 \\
& нейтральное отношение, как & 42,4 \\
\hline
\end{tabular}

Среди наиболее распространенных форм инфантилизирующих воздействий во внутрисемейном взаимодействии пожилые указывают на факты игнорирования их мнения: «Говорю: "Не хочу на дачу на все лето". Все равно вывозят, говорят, что мне там лучше будет» (женщина, 69 лет). Также упоминаются директивные указания: «В этот Новый год мне дочь сказала: "Папа, тебе уже хватит, иди-ка ты спать"» (мужчина, 72 года). Несколько реже респондентами отмечаются ситуации, в которых инфантилизация происходит посредством обесценивания их вклада в жизнь семьи: «Я их сnрашиваю: "Грибы солить на зиму?". Они говорят: "Соли, если хочешь". Чтобы отвязаться и уважить. А потом все выкидывают, чтобы я не видела» 
(женщина, 79 лет). В редких случаях респонденты упоминали об особых подарках, имеющих, с их точки зрения, инфантилизирующий подтекст: «Стылно сказать... Мне на юбилей семья подарила личный переносной унитаз на дачу. Как будто я маленькая, до уборной не добегу» (женщина, 75 лет). Во взаимодействии с социальными и медицинскими работниками говорят о преувеличенной заботе: «Сюсюкается, как с дитём: бабулечка то, бабулечка сё. Нашла себе бабулечку...» (женщина, 71 год).

В качестве наиболее распространенной реакции на инфантилизирующие воздействия пожилые люди отмечают, в первую очередь, негативные эмоции - обиду, досаду, раздражение: «Обидно, конечно, иногда даже всплакну» (женщина, 77 лет). В некоторых случаях пытаются сопротивляться инфантилизирующим воздействиям («продолжаю настаивать», женщина, 69 лет) или подыгрывать им, занимая при этом манипулятивную позицию: «Им хочется считать меня старым ребенком - да пожалуйста, больше заботиться будут, внимание уделять» (женщина, 67 лет). Однако примерно в четверти случаев респонденты выражают готовность согласиться с инфантилизирующими воздействиями: «не зря же говорят "старый что мальій"» (женщина, 77 лет). При этом инфантилизация пожилых зачастую воспринимается как нормативная форма взаимодействия не только со стороны представителей младших поколений, но и внутри когорты: 42,4\%, отмечающих проявления инфантилизирующих воздействий со стороны других людей, считают их закономерными.

Критериальный анализ показал, что инфантилизирующие воздействия в свой адрес чаще всего фиксируют пожилые люди, проживающие с детьми и/или внуками, не имеющие супруга и являющиеся пенсионерами $\left(\varphi^{*}=\right.$ 9,61, $\varphi^{*}=4,22, \varphi^{*}=6,00$ соответственно, $\left.\mathrm{p}<0,01\right)$.

\section{Обсуждение результатов}

Инфантилизация пожилых людей в процессах взаимодействия с ними является весьма распространенным явлением. Более четверти опрошенных (26,7\%) отмечают проявления инфантилизации по отношению к себе, чуть менее половины $(44,1 \%)$ признают существование этого явления в целом. Безусловно, на основе мнения респондентов невозможно точно оценить степень распространения инфантилизирующих практик взаимодействия с пожилыми людьми, поскольку не все они рефлексируются «адресатами» в полной мере. Тем не менее полученные результаты иллюстрируют значимость этой проблемы для психологического благополучия пожилых людей, что проявляется, в частности, в их преимущественно негативном отношении к инфантилизирующим воздействиям (57,6\% от общего количества ответов).

Однако нужно отметить, что у инфантилизации, помимо отрицательного эмоционального фона, возникающего у пожилых людей-«адресатов» воздействия, есть и другой негативный эффект, который с большой долей 
вероятности проявляется в поведении тех пожилых, кто соглашается с таким отношением к себе. Многочисленными исследованиями показано, что личностная ассимиляция негативных геронтостереотипов зачастую приводит к их последовательной реализации в поведении объектов стереотипизации и последующему закреплению в структуре личности в виде соответствующих им свойств (Levy, Leifheit-Limson 2009; Abrams et al. 2006). Таким образом, можно предположить, что согласие с инфантилизирующими воздействиями становится для пожилых людей фактором, снижающим степень их активности и самостоятельности. Эта гипотеза требует дальнейшей эмпирической проверки.

Учитывая неоднородность явления личностного инфантилизма, раскрывающегося в аспектах дефицита регуляторных, рефлексивных или нравственных свойств (Микляева 2016), необходимо обратить внимание на то, что инфантилизация пожилых людей осуществляется, прежде всего, по пути недооценки их регуляторных возможностей. Инфантилизирующие воздействия, основанные на недооценке рефлексивных или нравственных возможностей пожилых людей, респондентами отмечены не были.

Отдельного внимания заслуживает тот факт, что опыт инфантилизации связывается респондентами преимущественно со сферой внутрисемейного взаимодействия. Это противоречит современным тенденциям исследования инфантилизации пожилых людей в зарубежных странах, где проблема акцентируется в сфере медицинского обслуживания (Chih-ling, Shannon 2016; Marson 2013; Salari 2005). Что можно объяснить отмеченным выше доминированием в российском обществе медицинского дискурса старения и старости, в то время как в западных странах большое распространение имеет идея «успешного старения», акцентирующая внимание на возможностях активной и продуктивной старости (Bowling 2007; Depp, Jeste 2006; Baltes, Baltes 1993), снижая влияние негативных геронтостереотипов. В итоге, медицинский дискурс и характерные для него стереотипы беспомощной старости в зарубежных странах применимы преимущественно в медицинской сфере, тогда как за ее пределами тенденция к восприятию пожилых людей как несамостоятельных и беспомощных снижается, что позволяет им сохранять социальную активность и продуктивность. Эта гипотеза косвенно подтверждается полученными в нашем исследовании данными: инфантилизирующие воздействия чаще применяются в адрес тех пожилых людей, для которых характерно сокращение социальной активности.

Также необходимо отметить, что инфантилизирующее воздействие, по результатам исследования, оказалось преимущественно женской проблемой: пожилые женщины отмечают ее в три с половиной раза чаще, нежели пожилые мужчины. По всей вероятности, здесь находит отражение феномен «двойных стандартов старения», отмечаемый многими исследователями (Chrisler et al. 2016; Кац 2012; Handy, Davy 2007) и предполагающий разные ожидания относительно старения женщин и мужчин, которые 
обусловлены гендерными стереотипами. Так, стереотипный образ «ребенка» оказывается содержательно ближе стереотипному образу «женщины», чем образу «мужчины», прежде всего, в аспекте регуляторных аскриптивных свойств. В этой связи инфантилизация пожилых женщин является более «удобной» и воспринимается более «закономерной», чем инфантилизация пожилых мужчин.

\section{Заключение}

Таким образом, инфантилизирующая модель взаимодействия с пожилыми людьми, основанная на негативных геронтостереотипах и представляющая собой взаимодействие с пожилым человеком как с ребенком, имеет достаточно большое распространение. При этом она отмечается самими пожилыми людьми преимущественно во внутрисемейном взаимодействии, в котором в качестве субъектов инфантилизации чаще всего выступают дети и внуки. Инфантилизация пожилых людей опирается на представления об их регуляторном инфантилизме, связанном с неспособностью принимать самостоятельные решения, осуществлять продуктивную деятельность и нести ответственность за ее последствия. Вероятность инфантилизирующего отношения к пожилому человеку возрастает в том случае, если его социальная активность в основном ограничена взаимодействием внутри семьи, с представителями ее младших поколений. Помимо этого, подобные воздействия чаще адресованы пожилым женщинам, чем мужчинам.

Инфантилизирующие отношения представляют собой одну из практик социальной эксклюзии пожилых, широко распространенной в российском обществе (Максимова и др. 2017). Причины эксклюзии усматриваются в утрате экономических ресурсов и ресурсов социального влияния, влекущем за собой сокращение прав (Чукреев 2010), что в полной мере подтвердилось в нашем исследовании. Так, в инфантилизирующие отношения чаще всего оказываются вовлеченными те пожилые люди, которые в качестве единственного источника дохода располагают пенсией и проживают совместно с младшими родственниками, занимающими покровительственную позицию. Ограниченность ресурсов, в свою очередь, влечет за собой депривацию потребностей личности, удовлетворение которых крайне важно для поддержания благополучия (Суворова 2014). Можно отметить проявления депривации таких значимых потребностей пожилых людей, как потребность в уважении (указывают, что делать, не считаясь с возрастом), в эмоциональных контактах с близкими людьми (отвозят на дачу), в признании (лучше знают, что для пожилого человека хорошо).

Несмотря на негативное влияние инфантилизирующих отношений на личностное благополучие, сами пожилые часто склонны считать их закономерными. Аналогичное отношение к инфантилизации характерно и для представителей младших поколений, выступающих субъектами 
инфантилизации. Это придает явлению инфантилизации пожилых характер препятствия на пути формирования представлений о старости как о продуктивном периоде жизни. О необходимости преодоления дискриминации пожилых в различных сферах социальной жизни говорится довольно много, но проблема их инфантилизации (как форма эксклюзии) обсуждается крайне редко. Привлечение внимания к этой проблеме может стать первым шагом на пути преодоления ее негативных последствий, и, как следствие, внести вклад в распространение представлений о старости как активном и продуктивном периоде жизни.

\section{Выражения признательности}

Публикация подготовлена в рамках поддержанного РФФИ ОГОН научного проекта № 16-06-50031.

\section{Список источников}

Аликин И.А., Лукьянченко Н.В. (2012) Социально-нормативная повозрастная динамика родительского отношения к детям. Современные исследования социальных проблем, 10 (18). Доступно по ссылке: https:/elibrary.ru/item.asp?id=18263227 (дата обращения: 1 июня 2017).

Бельцова И.А. (2012) Концепция «успешное старение» как нормативный конструкт в формировании позитивного образа старости в демократическом обществе. Вестник экономики, права и социологии, (1):283-289.

Елютина М.Э., Чеконова Э.Е. (2004) Социальная геронтология. М.: Инфра-М.

Кац Ю.В. (2010) Стереотипизированная модель старения: гендерный аспект. Вестник Саратовского государственного технического университета, 2 (1):301-309.

Максимова С.Г., Ноянзина О.Е., Максимова М. М. (2017) Специфика межпоколенного взаимодействия в контексте исследования социальной эксклюзии: экспертные оценки. Вестник Алтайского государственного аграрного университета, 1 (147): 185-192.

Микляева А. В. (2014) Психология межвозрастных отнотений. М.: СВИВТ.

Микляева А.В. (2016) Зрелость и инфантилизм личности в социальных представлениях различных поколений. Азимут научных исследований. Педагогика и психология, 4 (17): 473-477.

Пучков П.В. (2009) Конщептуальные основания превенщии геронтологического насилия в современном российском обществе. Автореф. дис. д. социол. н. Саратов.

Смолькин А. А. (2004) Социокультурная динамика отношения к старости. Дисс. канд. социол. наук, Саратов.

Суворова И.Ю. (2014) Социальная эксклюзия как социально-психологический феномен. Сочиальная психология и общество, 5 (4):29-45.

Толстых Н.Н. (2015) Современное взросление. Консультативная психология и психотерапия, (4): 7-22.

Чукреев П.А. (2010) Социальная эксклюзия: теоретические и прикладные аспекты исследования. Вестник Бурятского государственного университета, (6): 172-177.

Abrams D., Eller A., Bryant J. (2006) An Age Apart: The Effects of Intergenerational Contact and Stereotype Threat on Performance and Intergroup Bias. Psychology and aging, (21): 691-702. 
Arnett J.J. (2011) Emerging Adulthood(s): The Cultural Psychology of a New Life Stage. In: J.J. Arnett (Ed.) Bridging Cultural and Developmental Approaches to Psychology: New Synthesis in Theory, Research, and Policy. Oxford: Oxford University Press:255-275.

Baltes P. B., Baltes M. M. (1993) Successful Aging: Perspectives from the Behavioral Sciences. New York: Cambridge University Press.

Bowling A. (2007) Aspirations for Older Age in the $21^{\text {st }}$ Century: What is Successful Aging. International Journal of Aging and Human Development, (64): 263-297.

Caporael L.R., Lukaszewski M.P., Culbertso, G.H. (1983) Secondary Baby Talk: Judgments by Institutionalized Elderly and Their Caregivers. Personality and Social Psychology, 44 (4): 746-754.

Castelli L., Zecchini A., Deamicis L. (2005) The Impact of Implicit Prejudice about the Elderly on the Reaction to Stereotype Confirmation and Disconfirmation. Current Psychology, (24): 134-146.

Chih-ling L., Shannon E. J. (2013) Dementia and Dementia Care in Asia - Taiwanese Experiences: Elders with Dementia in Two Different Adult Day Service (ADS) Environments. Aging \& Mental Health, 17 (8):942-951.

Chrisler J.C., Barney A., Palatino B. (2016) Ageism can be Hazardous to Women's Health: Ageism, Sexism, and Stereotypes of Older Women in the Healthcare System. Journal of Social Issues, 72 (1): 86-104.

Coupland J., Coupland N., Giles H., Henwood K. (1988) Accommodating the Elderly: Invoking and Extending a Theory. Language in Society, 17 (1): 1-41.

Couture P. (2007) Child Poverty: Love, Justice, and Social Responsibility. Atlanta: Chalice Press.

Depp C. A., Jeste D. V. (2006) Definitions and Predictors of Successful Aging: A Comprehensive Review of Larger Quantitative Studies. American Journal of Geriatric Psychiatry, (14): 6-20.

Gresham M. (1976) The Infantilization of the Elderly: A Developing Concept. Nursing Forum, (15): 195-210.

Handy J., Davy D. (2007) Gendered Ageism: Older Women's Experiences of Employment Agency Practices. Asia Pacific Journal of Human Resources, 45 (1):77-91.

Hockey J., James A. (1993) Infantilization as Social Discourse. In: J. Hockey (ed.) Growing up and Growing Old: Ageing and Dependency in Life Course. London: Sage: 9-44.

Levy B. R., Leifheit-Limson E. (2009) The Stereotype-Matching Effect: Greater Influence on Functioning when Age Stereotypes Correspond to Outcomes. Psychology and Aging, 24 (1):230-233.

Marson S. M., Powel R. M. (2014) Goffman and the Infantilization of Elderly Persons: A Theory in Development. Journal of Sociology \& Social Welfare, XLI (4): 143-158.

Marson S. (2013) Editorial: Is Infantilization Ethical? An Ethical Question. Journal of Social Work Values \& Ethics, 10 (1): 1.

Matusitz J., Breen G. M., Zhang N. J., Seblega B. K. (2013) Improving Nursing Home Resident Integrity by Optimizing Interpersonal Communication. Journal of Evidence-based Social Work, 10 (2): 63-72.

Ryan E.B., Kennaley D.E., Pratt M.W., Shumovich M. A. (2000) Evaluations by Staff, Residents, and Community Seniors of Patronizing Speech in the Nursing Home: Impact of Passive, Assertive, or Humorous Responses. Psychology \& Aging, 15 (2):272-286.

Salari S. M. (2005) Infantilization as Elder Mistreatment: Evidence from Five Adult day Care Centers. Journal of Elder Abuse \& Neglect, 17 (4): 53-91. 
Anastasia Miklyaeva

\section{THE INFANTILIZATION OF THE ELDERLY IN EVERYDAY INTERACTION: PROBLEM STATEMENT}

The transformation of relations to the elderly and the spread of an ideology of productive aging are factors that impede viewing old age as an active and productive part of life. Infantilization can be understood as an interaction model based on negative gerontostereotypes that tends to treat the elderly as if they were children. Gerontostereotypes contain the notion that the elderly lose many opportunities, becomes 'like a child', furthering the infantilization of old people as a normative phenomenon. This article presents findings about the infantilization of elderly people in daily interaction. 118 elderly people aged 64-81 year took part in the study. Data was collected with the modified method of Dembo-Rubinshtein, using structured interviews and following content analysis. The findings show the prevalence of infantilizing relations towards the elderly. Respondents reported the effects of infantilization in family interaction. The basis of this is a regulatory infantilism associated with the inability to make independent decisions, to carry out productive activities and be responsible for their consequences. Infantilization is characteristic of old people with restricted social activity: those not working, not having a spouse and living with their children and grandchildren. Infantilizing relations towards the elderly has a negative impact on their psychological well-being. However, despite the negative impact of infantilization, old people quite often tend to regard them as justified. We formulate the hypothesis that the prevalence of infantilizing relations in the family sphere is an effect of the medical discourse on old age and ageing in Russian society (in contrast to the discourse on 'successful aging'). Also, we draw conclusions on the 'double standard of aging'. We conclude that the discussion of the negative consequences of infantilization may be the first step in overcoming this phenomenon, thus bringing about the assimilation of the idea of productive aging as part of the social conception of old age.

Keywords: infantilization, gerontostereotypes, interaction, elderly, family.

DOI: 10.17323/727-0634-2018-16-1-109-124

\section{References}

Abrams D., Eller A., Bryant J. (2006) An Age Apart: The Effects of Intergenerational Contact and Stereotype Threat on Performance and Intergroup Bias. Psychology and aging, (21): 691-702.

Anastasia V. Miklyaeva - Dr. (Psychological), Associate Professor, Professor of the Chair 'Human psychology', Herzen State Pedagogical University of Russia, Saint-Petersburg, Russian Federation. Email: a.miklyaeva@gmail.com 
Alikin I. A., Luk'yanchenko N.V. (2012) Sotsial'no-normativnaya povozrastnaya dinamika roditel'skogo otnosheniya k detyam [Socio-Normative Age-Specific Dynamics of Parental Attitude to Children]. Sovremennye issledovaniya sotsial'nykh problem (elektronnyy nauchnyy zhurnal) [Modern Research of Social Problems], 10(18). Availible at: https://elibrary.ru/item.asp?id=18263227 (accessed 01 June 2017).

Arnett J.J. (2011) Emerging Adulthood(s): The Cultural Psychology of a New Life Stage. J.J. Arnett (ed.) Bridging Cultural and Developmental Approaches to Psychology: New Synthesis in Theory, Research, and Policy. Oxford: Oxford University Press:255-275.

Baltes P. B., Baltes M. M. (1993) Successful Aging: Perspectives from the Behavioral Sciences. New York: Cambridge University Press.

Bel'tsova I.A. (2012) Kontseptsiya 'uspeshnoe starenie' kak normativnyy konstrukt v formirovanii pozitivnogo obraza starosti v demokraticheskom obshchestve [The Concept of Prosperous Ageing as a Normative Construct in Forming of Positive Image of Ageing in Democratic Countries]. Vestnik ekonomiki, prava i sotsiologii [The Review of Economy, the Law and Sociology], (1):283-289.

Bowling A. (2007) Aspirations for Older Age in the 21st Century: What is Successful Aging? International Journal of Aging and Human Development, (64): 263-297.

Caporael L.R., Lukaszewski M.P., Culbertso G. H. (1983) Secondary Baby Talk: Judgments by Institutionalized Elderly and their Caregivers. Personality and Social Psychology, 44 (4): 746-754.

Castelli L., Zecchini A., Deamicis L. (2005) The Impact of Implicit Prejudice about the Elderly on the Reaction to Stereotype Confirmation and Disconfirmation. Current Psychology, (24): 134-146.

Chih-ling L., Shannon E. J. (2013) Dementia and Dementia Care in Asia - Taiwanese Experiences: Elders with Dementia in Two Different Adult Day Service (ADS) Environments. Aging \& Mental Health, 17 (8): 942-951.

Chrisler J. C., Barney A., Palatino B. (2016) Ageism can be Hazardous to Women's Health: Ageism, Sexism, and Stereotypes of Older Women in the Healthcare System. Journal of Social Issues, 72 (1): 86-104.

Chukreev P. A. (2010) Sotsial'naya eksklyuziya: teoreticheskie i prikladnye aspekty issledovaniya [Social Exclusion: Theoretical and Applied Aspects of Research]. Vestnik Buryatskogo gosudarstvennogo universiteta [Bulletin of Buryat State University], (6): 172-177.

Coupland J., Coupland N., Giles H., Henwood K. (1988) Accommodating the Elderly: Invoking and Extending a Theory. Language in Society, 17 (1): 1-41.

Couture P. (2007). Child Poverty: Love, Justice, and Social Responsibility. Atlanta: Chalice Press.

Depp C. A., Jeste D. V. (2006) Definitions and Predictors of Successful Aging: A Comprehensive Review of Larger Quantitative Studies. American Journal of Geriatric Psychiatry, (14): 6-20. 
Elyutina M.E., Chekonova E.E. (2004) Sotsial'naya gerontologiya [Social Gerontology]. Moscow: Infra-M.

Gresham M. (1976) The Infantilization of the Elderly: A Developing Concept. Nursing Forum, (15): 195-210.

Handy J., Davy D. (2007) Gendered Ageism: Older Women's Experiences of Employment Agency Practices. Asia Pacific Journal of Human Resources, 45 (1): 77-91.

Hockey J., James A. (1993) Infantilization as Social Discourse. J. Hockey (ed.) Growing up and Growing Old: Ageing and Dependency in Life Course. London: Sage: 9-44.

Kats Yu.V. (2010) Stereotipizirovannaya model' stareniya: gendernyy aspect [The Stereotypified Model of Aging: Gender Aspect]. Vestnik Saratovskogo gosudarstvennogo tekhnicheskogo universiteta [Vestnik Saratov State Technical University], 2 (1):301-309.

Levy B. R., Leifheit-Limson E. (2009) The Stereotype-matching Effect: Greater Influence on Functioning when Age Stereotypes Correspond to Outcomes. Psychology and Aging, 24 (1): 230-233.

Maksimova S. G., Noyanzina O.E., Maksimova M. M. (2017) Spetsifika mezhpokolennogo vzaimodeystviya v kontekste issledovaniya sotsial'noy eksklyuzii: ekspertnye otsenki [Specific Features of Intergenerational Interaction in the Context of Research of Social Exclusion: Expert Evaluations]. Vestnik Altayskogo gosudarstvennogo agrarnogo universiteta [Bulletin of Altai State Agrarian University], 1 (147): 185-192.

Marson S. (2013) Editorial: Is Infantilization Ethical? An Ethical Question. Journal of Social Work Values \& Ethics, 10 (1): 1.

Marson S. M., Powel R. M. (2014) Goffman and the Infantilization of Elderly Persons: A Theory in Development. Journal of Sociology \& Social Welfare, XLI (4): 143-158.

Matusitz J., Breen G. M., Zhang N. J., Seblega B. K. (2013) Improving Nursing Home Resident Integrity by Optimizing Interpersonal Communication. Journal of Evidence-based Social Work, 10 (2): 63-72.

Miklyaeva A. V. (2014) Psikhologiya mezhvozrastnykh otnosheniy [Psychology of Interage Relations]. Moscow: SVIVT.

Miklyaeva A. V. (2016) Zrelost' i infantilizmlichnosti v sotsial'nykh predstavleniyakh razlichnykh pokoleniy [Personal Maturity and Infantilism in the Social Beliefs of Different Generations]. Azimut nauchnykh issledovaniy. Pedagogika i psikhologiya [ASR: Pedagogy and Psychology], 4 (17): 473-477.

Puchkov P. V. (2009) Kontseptual'nye osnovaniya preventsii gerontologicheskogo nasiliya $v$ sovremennom rossiyskom obshchestve [Conceptual Basis for Preventing of Gerontological Violence in the Modern Russian Society]: avtoref. dis. d. sotsiol. n., Saratov.

Ryan E. B., Kennaley D.E., Pratt M. W., Shumovich M. A. (2000) Evaluations by Staff, Residents, and Community Seniors of Patronizing Speech in the Nursing Home: Impact of Passive, Assertive, or Humorous Responses. Psychology \& Aging, 15 (2):272-286.

Salari S. M. (2005) Infantilization as Elder Mistreatment: Evidence from Five Adult Day Care Centers. Journal of Elder Abuse \& Neglect, 17 (4): 53-91. 
Smol'kin A.A. (2004) Sotsiokul'turnaya dinamika otnosheniya k starosti [Socio-Cultural Dynamics of Attitudes to Old Age]: diss. kand. sotsiol. nauk, Saratov.

Suvorova I. Yu. (2014) Sotsial'naya eksklyuziya kak sotsial'no-psikhologicheskiy fenomen [Social Exclusion as a Social-Psychological Phenomenon]. Sotsial'naya psikhologiya i obshchestvo [Social psychology and society], 5 (4):29-45.

Tolstykh N. N. (2015) Sovremennoe vzroslenie [Modern Maturation]. Konsul'tativnaya psikhologiya i psikhoterapiya [Counseling Psychology and Psychotherapy], (4): 7-22. 